\title{
Evaluation of How Integrative Oncology Services Are Valued between Hematology/Oncology Patients and Hematologists/Oncologists at a Tertiary Care Center
}

\author{
D. M. Hansra $\mathbb{D}^{1,2,3}$ K. McIntyre, ${ }^{4}$ J. Ramdial, ${ }^{2,3}$ S. Sacks, ${ }^{4}$ C. S. Patrick, ${ }^{4}$ \\ J. Cutler $\mathbb{D},{ }^{4}$ B. McIntyre $\mathbb{D},{ }^{4}$ K. Feister $\mathbb{D},{ }^{4}$ M. Miller, ${ }^{4}$ A. K. Taylor $\mathbb{D},{ }^{4}$ F. Farooq, ${ }^{2,3}$ \\ J. Antunez de Mayolo, ${ }^{5}$ and E. Ahn ${ }^{1,3,4}$ \\ ${ }^{1}$ Cancer Treatment Centers of America, Atlanta, GA, USA \\ ${ }^{2} J a c k s o n$ Memorial Hospital, Miami, FL, USA \\ ${ }^{3}$ Sylvester Comprehensive Cancer Center, Miami, FL, USA \\ ${ }^{4}$ Miller School of Medicine, University of Miami, Miami, FL, USA \\ ${ }^{5}$ University of Miami Health System, Miami, FL, USA \\ Correspondence should be addressed to D. M. Hansra; dmhansra@gmail.com
}

Received 5 October 2017; Revised 28 December 2017; Accepted 4 January 2018; Published 12 April 2018

Academic Editor: Konrad Urech

Copyright (c) 2018 D. M. Hansra et al. This is an open access article distributed under the Creative Commons Attribution License, which permits unrestricted use, distribution, and reproduction in any medium, provided the original work is properly cited.

\begin{abstract}
Evidence regarding opinions on integrative modalities by patients and physicians is lacking. Methods. A survey study was conducted assessing how integrative modalities were valued among hematology/oncology patients and hematologists and oncologists at a major tertiary medical center. Results. 1008 patients and 55 physicians were surveyed. With the exception of support groups, patients valued nutrition services, exercise therapy, spiritual/religious counseling, supplement/herbal advice, support groups, music therapy, and other complimentary medicine services significantly more than physicians $(P \leq 0.05)$. Conclusion. With the exception of support groups, patients value integrative modalities more than physicians. Perhaps with increasing education, awareness, and acceptance by providers and traditional institutions, integrative modalities could be equally valued between patients and providers. It is possible that increased availability and utilization of integrative oncology modalities at tertiary hospital sites could improve patient satisfaction, quality of life, and other clinical endpoints.
\end{abstract}

\section{Background}

Evidence shows increased patient utilization of various integrative care modalities in oncology. In part, patients desire greater self-empowerment to manage their symptoms and improve quality of life and overall outcomes. Furthermore with increasing globalization, elements of eastern medicine are widely being recognized and embraced by patients and medical professionals. Measurements of patient and physicians opinions regarding the importance of integrative care are lacking. We aim to compare how National Comprehensive Cancer Network (NCCN) recommended "integrative care" modalities are valued between hematology/oncology physicians and patients.

\section{Methods}

After an institutional review board approval was obtained, a survey study was administered to 1008 hematology and oncology patients and 55 hematologists and oncologists at two outpatient clinical sites at a major tertiary medical center in Miami, Florida, from June 2013 to October 2015. Surveys were administered in the outpatient setting by nursing staff after consent was obtained. Patients filled out surveys in the waiting area; then they were placed in a locked box. Physicians filled out surveys in their office and were placed in a locked box. Both physician and patient surveys were anonymous. The survey was administered in both Spanish and English. The patient survey consisted of 7 questions 
assessing opinions on integrative care asking: "In addition to standard care, it is important to incorporate/provide the following services in my cancer plan": (1) nutrition services, (2) exercise therapy, (3) spiritual/religious counseling, (4) supplement/herbal advice, (5) support groups, (6) music therapy, and (7) other complimentary medicine services (acupuncture, massage, and relaxation therapy). Answers were recorded on a 5-point scale ( $1=$ highly disagree, $2=$ disagree, 3 = neutral, $4=$ agree, and $5=$ highly agree) and then converted into 2 categories $(1,2,3=$ neutral/disagree versus $4,5=$ agree). The physician survey consisted of the same 7 questions assessing opinions on integrative care asking: "In addition to standard care, it is important to incorporate/provide the following services for my patient": (1) nutrition services, (2) exercise therapy, (3) spiritual/religious counseling, (4) supplement/herbal advice, (5) support groups, (6) music therapy, and (7) other complimentary medicine services (acupuncture, massage, and relaxation therapy). Answers were recorded on a 5-point scale $(1=$ highly disagree, 2 = disagree, $3=$ neutral, $4=$ agree, and 5 $=$ highly agree) and then converted into 2 categories $(1,2,3=$ neutral/disagree versus 4,5 = agree). Then, Fisher's exact test with two sided $P$ value was used to compare the responses between patients and physicians. Demographics collected in the survey included age, gender, race, and ethnicity. Clinical information collected included cancer diagnosis. Inclusion criteria include adult outpatients 18 years old or older with any hematologic or oncologic malignancy. Exclusion criteria include inpatients, patients younger than 18 years old, and those with nonmalignant diagnoses.

\section{Results}

1008 patients were enrolled from June 2013 to October 2015. The mean patient age was 55 years with a range of 18-88 years. $45 \%$ of patients were male and $55 \%$ of patients were female. $62 \%$ of patients were Hispanic versus $38 \%$ of patients not Hispanic. $16 \%$ of patients were white, $14 \%$ black/African American, 2\% Asian/Pacific Islander, and 6\% other. $21 \%$ of patients had hematologic malignancies versus $79 \%$ of patients having solid malignancies. 55 physicians were enrolled from June 2013 to October 2015. The mean physician age was 47 years with a range of $29-75$ years. $70 \%$ of physicians were male and $30 \%$ of patients were female. $38 \%$ of physicians were Hispanic versus $62 \%$ of physicians not Hispanic. $64 \%$ of patients were white, $14 \%$ black/African American, $11 \%$ Asian/Pacific Islander, and $11 \%$ other. Survey results were as follows: $84 \%$ of patients agree that nutritional advice is important versus $69 \%$ of physicians, $P=0.0077 .85 \%$ of patients agree that exercise therapy is important versus $71 \%$ of physicians, $P=0.0120 .68 \%$ of patients agree that spiritual/religious counseling is important versus $47 \%$ of physicians, $P=0.0031 .85 \%$ of patients agree that advice on supplement/herbal therapies is important versus $44 \%$ of physicians, $P<0.0001 .60 \%$ of patients agree that music therapy is important versus $28 \%$ of patients, $P<0.0001 .77 \%$ of patients agree that "other complementary services" including acupuncture, massage, and relaxation therapy are important versus $47 \%$ of physicians, $P<0.0001$. $71 \%$ of patients agree that support groups are important versus $66 \%$ of physicians, $P=0.4377$.

\section{Discussion}

Our study reveals that the majority of patients felt that in addition to standard of care it was important to include nutrition services, exercise therapy, spiritual/religious counseling, supplement/herbal advice, support groups, music therapy, and other complimentary medicine services into their care plan. With the exception of support groups, patients valued integrative modalities more than physicians.

The exact mechanism for the significant discrepancies observed in our study between physicians' and patients' value of integrative modalities is unclear. One major contributing factor may be a physician knowledge gap. Several studies show that physicians currently lack the knowledge, confidence, and training to provide proper guidance to the increasing number of patients who are using integrative modalities [1-6]. A lack of evidence-based information about efficacy, safety, and drug interactions with integrative modalities, as well as a lack of formal training, is thought to be responsible for this deficit [1-6]. In response to increasing use of integrative modalities professional standards are beginning to be issued for pharmacists and physicians and these standards are an important source of guidance with respect to providing patient counseling and utilizing these treatments $[2,5,7,8]$.

The Federation of State Medical Boards (FSMB) has also responded to the increased interest in integrative modalities by issuing its own guidelines $[3,9]$. The board recognizes that consistency in standards for evaluating healthcare practices is necessary, whether they are applied to conventional medicine or to integrative modalities [3,9]. This is highly important as integrative modalities are now increasingly recognized by traditional institutions as having true medicinal value and are held to the same standards as traditional medicine. Furthermore increasing medical schools are offering education in integrative modalities in their curriculums [10]. Perhaps with increasing education, awareness, and acceptance by providers and traditional institutions integrative modalities could be equally valued between patients and providers. Given that providers in traditional institutions, such as tertiary care hospital sites, execute patients' orders, and referrals, it is possible that increased education and awareness of integrative modalities could translate into increased utilization of such services.

In the following sections, we discuss and highlight the evidence behind the integrative modalities with significant disparities.

4.1. Exercise. The literature shows that exercise improves quality of life and physical function in patients with cancer [11]. Randomized trials have shown that exercise training is safe, tolerable, and effective for most patients [12-21]. Aerobic and resistance training programs after cancer treatment can improve cardiovascular fitness and strength and can have positive effects on balance, body composition, fatigue, emotional well-being, and quality of life [12-21]. 
Cancer related fatigue is a common and distressing symptom in cancer patients. Several reviews and meta-analyses of clinical trials show that not only is exercise therapy safe in cancer patients but it also significantly reduces cancer related fatigue $[19,22,23]$. Furthermore, one meta-analysis of clinical trials showed exercise therapy to be superior to pharmaceuticals in reducing cancer related fatigue [24].

Numerous observational studies have consistently found that physical activity is linked to decreased cancer recurrence, incidence, and increased survival for certain tumor types [2539]. Conversely, inactivity and sedentary behaviors are risk factors for cancer incidence and mortality and also impact mood and quality of life, independent of recreational or occupational physical activity [40-47]. Given the overwhelming evidence all patients should engage in physical activity if possible. Even light physical activity has been shown to improve physical functioning [48]. At minimum patients should be counseled to avoid sedentary behaviors.

4.2. Acupuncture. Acupuncture is increasingly used as a therapeutic measure for managing cancer related symptoms. Numerous trials have demonstrated that acupuncture is an effective adjunct in treating cancer related pain [49-52]. Acupuncture has also demonstrated efficacy in relieving side effects of medications such as aromatase inhibitor induced arthralgias [53, 54]. Also, acupuncture may complement other treatments for neuropathic pain by inhibiting various opioid receptors [55]. Acupuncture is also helpful in the treatment and prevention of chemotherapy-induced and postoperative nausea and vomiting [11, 49, 56, 57]. Additionally, acupuncture may also address sleep disturbance, anxiety, drowsiness, and fatigue [56-59] but more research is needed to strengthen the validity of managing other cancer related symptoms [60-62]. Interestingly, acupuncture research has had a twofold higher growth rate compared to biomedical research in the last two decades [63]. Demand for acupuncture treatment in managing cancer outcomes has increased [64] in tandem with increased research.

4.3. Music Therapy. There are many benefits of music therapy for patients including improving mood, decreasing stress, pain, anxiety level, and enhancing relaxation [65]. When used in conjunction with conventional cancer treatments, music therapy has been found to help patients promote a better quality of life [66]. Music therapy includes both passive and active forms. Passive music therapy entails a patient listening to live or recorded music whereas active music therapy techniques include engaging the patient in singing, music composition, and instrument playing.

One study examined 51 studies on 1867 patients exposed to passive music therapy and evaluated its effects in both children and adults [67]. The results showed that listening to music reduced not only pain intensity levels but also opioid requirements [67]. One large systematic review of over 200 randomized controlled trials (RCT) showed that passive music therapy improves depression and anxiety in female patients with breast cancer [68].

The data on active music therapy in cancer patients is less robust than passive music therapy. One prospective study in terminally ill cancer patients utilizing components of active music therapy showed that the majority of patients experienced a positive benefit [69]. In addition to music therapy other forms of art therapy have been shown to be of benefit in cancer patients. For example, one systematic review and meta-analysis of clinical trials that included clinical trials utilizing dance and movement therapy and art therapy working with visual arts materials have beneficial effects on anxiety in patients with breast cancer [70].

Music can be easily delivered to patients in a variety of formats such as live or recorded concerts and performances on tapes, video, and mobile devices. Also music therapy can easily be delivered in any setting such as the comfort of one's own home, chemotherapy infusion suite, or hospital room. Furthermore, other forms of art therapy such as active music therapy and visual art therapy are safe, relatively inexpensive, and with no risk of systemic side effects to the patient. Due to the favorable risk/benefit profile all patients should be offered music therapy and art therapy as a part of their cancer care.

4.4. Herbal Medicine, Vitamins, and Mineral Supplements. Evidence shows increased utilization of herbal medications among cancer patients $[71,72]$. There are numerous herbal medications that claim to have anticancer effects but in general high quality clinical evidence is lacking. There is good evidence showing antitumor activity in laboratory studies for a variety of herbal compounds. For example, green tea (Camellia sinensis) and Mistletoe (Viscum album) have demonstrated antineoplastic effects such as antiproliferative or apoptosis-inducing in various cancer cell lines [73-81]. Also Graviola (Annona muricata) has been shown to inhibit tumorgenicity by inhibiting multiple signaling pathways in pancreatic and breast cancer cell lines [82].

Herbal medications have also been used to manage side effects. For example, Mistletoe has been well studied and several reviews and clinical trials have shown that the application of Mistletoe extract has been associated with a reduction of chemotherapy-related side effects as well as an improvement in quality of life during chemotherapy [81, 83-88]. Ginger has been used to relieve chemotherapy-induced nausea and vomiting [89-91]. Also, St. John's Wort (Hypericum perforatum) is utilized for antidepressant properties [92], and Kava kava (Piper methysticum) was found to decrease anxiety in meta-analyses of multiple randomized trials [93, 94]. Though patients often perceive herbal medicine as more natural and hence safer than other more conventional treatments, concerns about their safety and potential risks remain [72, 95]. Kava kava was withdrawn after reports of hepatotoxicity and liver failure secondary to its use emerged [96]. In addition, inadequate quality control of these products may give rise to contamination of the herbs with heavy metals, pesticides, and so forth [72]. For example, PC-SPES, a mixture of herbs, was found to have considerable antineoplastic effects [71, 9799], but it was later withdrawn when reports emerged that it may be contaminated with Warfarin and may induce bleeding diathesis $[99,100]$.

Drug-herb interactions also remain of great concern regarding potential harmful interactions and increased toxicity, as well as decreased efficacy of prescribed treatments 
[72, 95]. For example, Ginkgo biloba and Ginseng (Panax ginseng) are CYP3A4 and CYP2C19 inhibitors and thus might interact with a variety of chemotherapy agents.

It is estimated that $79-85 \%$ of cancer survivors take vitamin or mineral supplementation, often without disclosing this information to their providers [101-103]. Of concern, an analysis of dietary supplements found that many supplements contain unlisted ingredients or banned pharmaceutical ingredients $[32,104]$ which could be potentially toxic to patients. No clear evidence supports an effect of dietary supplements for cancer prevention, control, or recurrence $[32,105,106]$. Given the high percentage of patient's usage of herbal medication and supplements, we recommend that providers should assess all herbal medication and supplement use and prescribe supplements in patients only with documented or at risks deficiencies. If patients desire usage of herbal medications, they should be referred to an integrative certified specialist or oncologist with experience in this area. Furthermore patients with interest in taking herbal medications and supplements should be encouraged to participate in clinical trials when indicated.

4.5. Massage Therapy. Evidence shows massage therapy benefits cancer patients by relieving symptoms and improving well-being [107]. A study of 1290 patients treated with massage therapy experienced a $50 \%$ reduction in symptom scores for fatigue, nausea, and anxiety [108]. The same study additionally found that the effects of massage therapy were greater for outpatients, with a $10 \%$ increase in improvement over inpatients [109]. Separate RCTs have also demonstrated that massage therapy leads to reductions in pain, nausea, fatigue, perceived stress, and cortisol levels in breast cancer patients undergoing chemotherapy [109-111]. Furthermore, massage therapy has been shown to decrease depression, reduce mood disturbances, and anger in patients [110,112, 113]. Also, one meta-analysis of 18 RCTs including 950 patients showed significant favorable effects on fatigue and negative emotions [114]. Reviews studying the outcomes of massage therapy have found that it may reduce pain and anxiety short-term; however the long-term benefits remain unclear $[107,115,116]$. With regard to implementation of massage therapy, a recent study at chemoinfusion centers found that massage can be safely administered at chemoinfusion suites [117]. Given the excellent benefit-risk ratio of message therapy, this modality should be offered as indicated to interested patients.

4.6. Nutrition. Numerous studies have shown that various aspects of nutrition are important in cancer patients. Some studies focus on the importance of avoiding malnutrition and assessing nutritional status in cancer patients [118]. For example, it has been shown that early identification of nutritional deficiencies can improve quality of life and survival in patients with non-small cell lung cancer (NSCLC) and that malnutrition is an independent prognostic factor in advanced NSCLC [119].

Nutrition has also been shown to play an important role in the perioperative setting. For example, assessments of nutritional status and use of prognostic indices can help predict postoperative complications and clinical outcomes in patients with gastrointestinal cancers [119]. Additionally, the preoperative prognostic nutritional index (PNI) is an independent predictor of survival in patients with renal cell carcinoma and gastric carcinoma [120, 121].

Larger studies have focused on outcomes related to nutritional intake in cancer patients. Studies have shown that healthy dietary patterns are associated with decreased risk of cancer development overall [121, 122]. A study in England with $>65000$ participants showed that at least 7 servings per day of fruits and vegetables decreased cancer incidence by $25 \%$ [123].

Studies have also shown that healthy dietary patterns are associated with a decrease in cancer recurrence and improved outcomes in survivors. For example, in survivors of stage III colon cancer, a diet with more fruits, vegetables, chicken, and fish showed improved outcomes in terms of cancer recurrence and overall survival [124]. High dietary glycemic load has also been associated with increased risk of recurrence and mortality in survivors, as was high intake of red and processed meat $[125,126]$. Also, meta-analyses have shown that whole grain intake is inversely associated with cancer mortality [127].

Evidence also exists for tailored nutrition to specific cancers. For example, omega 3 polyunsaturated fatty acids (PUFAs) have been shown to be beneficial after surgery performed for gastric cancer, have been shown to play a role in inflammation in Colorectal Cancer [128], and have been shown to improve outcomes and prognosis in pancreatic cancer patients [129]. Additionally, a study of 4282 women suggested that an olive oil/Mediterranean diet reduced the risk of invasive breast cancer [130].

Of importance, the interrelation between obesity and nutrition plays an important role in cancer outcomes. It has been shown that weight gain or being overweight or obese can worsen a survivor's risk for cancer recurrence or death. For example, a meta-analysis showed that there is a correlation between BMI and higher risk of total and breast cancer specific mortality [131]. Another study showed that survivors of stage II and III colon cancer enrolled in NSABP trials from 1989-1994 with a BMI of 35 or greater had an increased risk of disease recurrence and death [132]. Furthermore, there have been studies showing that weight loss or gain increases mortality risk in survivors suggesting that weight maintenance is optimal [133].

Per current evidence and NCCN guidelines, the following is recommended: in terms of food volume, fruits and vegetables should take up half of the volume on the plate $(30 \%$ vegetables, $20 \%$ fruit), whole grains should be $30 \%$ of the plate, and protein should be $20 \%$ of the plate. In terms of food components, fat in the diet should be obtained from plant oils, avocados, seeds, nuts, and fatty fish. Carbohydrates should be obtained from fruits and vegetables, legumes, and whole grains. Proteins should be obtained from poultry, fish, legumes, low fat dairy foods, and nuts. In addition, limited intake of red or processed meats and refined sugars is encouraged. Referral to a Certified Specialist in Oncology Nutrition (CSO) if available is ideal [134]. Furthermore, overweight/obese patients should discuss nutrition with their providers, specifically portion control and tracking calories to 
normalize BMI. Those who are underweight should increase frequency of eating and avoid fluid intake with meals [135].

4.7. Spiritual and Religious Support. Spiritual and religious support has become increasingly important component of supportive care for cancer patients as this is associated with improved mental health in cancer patients [136] and quality of life [137-139]. Also, attendance at religious services is associated with lower cancer related mortality [140]. Ideally, religion and spirituality can aid patients in identifying positive coping skills, managing grief [141], finding new goals, redefining hope, and realizing purpose and peace in suffering [142]. In our study, a majority of patients (68\%) felt that religious and spiritual counseling was important to their cancer care which is consistent with one study by Balboni et al. showing a majority of patients ( $88 \%$ ) considered religion important to their care [143]. In the same study, $72 \%$ of patients reported receiving little to no support from their medical system [143]. Religious and spiritual care results not only in clinical improvements but also in customer satisfaction [144]. Although there are mixed reports on outcomes from religion and spirituality studies, there is overwhelming evidence that demonstrates positive clinical effects [145-150]. All patients should be assessed for religious and spiritual related distress and be referred to a chaplaincy professional upon request.

\section{Study Limitations}

Our study has several limitations. First, survey studies are prone to response bias. In terms of demographics, our patient population was predominantly Hispanic and white; therefore caution should be used in extrapolating our data to the general hematology/oncology populations. Last, our study was conducted in South Florida which has unique sociocultural influences compared to other states so again extrapolation of this study to the general cancer population is cautioned.

\section{Study Strengths}

Our study enjoyed several strengths including a large number of patients (over 1000) and a large number of physicians (over 50) and the power of the study was adequate for confident analysis. Furthermore, we followed strict guidelines to maintain anonymity among participants to minimize bias. Also, this is the first and largest study addressing opinions integrative modalities in both hematology oncology patients and providers. Although the patient population was predominately white Hispanic, there was a significant amount of population heterogeneity included in this study. Last, the physician population was heterogeneous which likely reflects general hematologist oncologist population in the United States.

\section{Conclusions}

The majority of patients feel that in addition to standard of care it is important to include nutrition services, exercise therapy, spiritual/religious counseling, supplement/herbal advice, support groups, music therapy, and other complimentary medicine services such as acupuncture, massage, and relaxation therapy into their care plan. With the exception of support groups, patients value integrative modalities more than their physicians. Since physicians formulate and execute patient care plans, it is important that they recognize these modalities as desired by the majority of patients and also that these modalities are endorsed by the NCCN as category 1 and $2 \mathrm{~A}$ recommendations. Addressing these major disparities between physician and patients should be a top priority for tertiary care sites. Perhaps with increasing education, awareness, and acceptance by providers and traditional institutions, integrative modalities could be equally valued between patients and providers. Furthermore, it is possible that increased availability and utilization of integrative oncology modalities at tertiary hospital sites could improve patient satisfaction, quality of life, and other clinical endpoints.

\section{Disclosure}

An abstract for this research was originally published in the Journal of Clinical Oncology [151].

\section{Conflicts of Interest}

The authors declare that there are no conflicts of interest to disclose.

\section{References}

[1] J. D. Dunn, H. E. Cannon, T. Lewis, and L. Shane-McWhorter, "Development of a complementary and alternative medicine (CAM) pharmacy and therapeutics (P\&T) subcommittee and CAM guide for providers." Journal of managed care pharmacy: JMCP, vol. 11, no. 3, pp. 252-258, 2005.

[2] D. Kwan, K. Hirschkorn, and H. Boon, "U.S. and Canadian pharmacists' attitudes, knowledge, and professional practice behaviors toward dietary supplements: A systematic review," BMC Complementary and Alternative Medicine, vol. 6, article no. 31, 2006.

[3] M. McHuges and B. N. Timmermann, "A Review of the Use of CAM Therapy and the Sources of Accurate and Reliable Information," Journal of Managed Care Pharmacy, vol. 11, no. 8, pp. 695-703, 2005.

[4] P. Gardiner, R. S. Phillips, K. J. Kemper, A. Legedza, S. Henlon, and A. D. Woolf, "Dietary supplements: Inpatient policies in US children's hospitals," Pediatrics, vol. 121, no. 4, pp. e775-e781, 2008.

[5] "Most doctors not knowledgeable about herbals HealthDay News April 2010," http://www.modernmedicine.com/\%5Bnodesource-domain-raw $\% 5 \mathrm{D} /$ news/clinical/clinical-pharmacology/ most-doctors-not-knowledgeable-about-he.

[6] S. A. Waldman and A. Terzic, Pharmacology and Therapeutics: Principles to Practice, W. B. Saunders, Ed., Elsevier, Philadelphia, 2008.

[7] D. J. Kroll, "American Society of Health-System Pharmacists ASHP statement on the use of dietary supplements," Am J Health Syst Pharm, vol. 61, pp. 1707-1711, 2004.

[8] L. G. Miller, A. Hume, I. M. Harris et al., "White paper on herbal products," Pharmacotherapy, vol. 20, no. 7 I, pp. 877-891, 2000. 
[9] "Federation of State Medical Boards (FSMB) Model Guidelines for the Use of Complementary and Alternative Medicine in Medical Practice April 2002," http://www.fsmb.org/globalassets/ advocacy/policies/model-guidelines-for-the-use-of-complementaryand-alternative-therapies-in-medical-practice.pdf.

[10] V. S. Cowen and V. Cyr, "Complementary and alternative medicine in US medical schools," Advances in Medical Education and Practice, vol. 2015, no. 6, pp. 113-117, 2015.

[11] L. Buffart, "Effects and moderators of exercise on quality of life and physical function in patients with cancer: An individual patient data meta-analysis of 34 RCTs," Cancer treatment reviews, vol. 52, pp. 91-104, 2017.

[12] J. C. Brown, T. B. Huedo-Medina, L. S. Pescatello, S. M. Pescatello, R. A. Ferrer, and B. T. Johnson, "Efficacy of exercise interventions in modulating cancer-related fatigue among adult cancer survivors: a meta-analysis," Cancer Epidemiology, Biomarkers \& Prevention, vol. 20, no. 1, pp. 123-133, 2011.

[13] S. I. Mishra, R. W. Scherer, P. M. Geigle et al., "Exercise interventions on health-related quality of life for cancer survivors," Cochrane Database of Systematic Reviews, vol. 8, Article ID CD007566, 2012.

[14] R. M. Speck, K. S. Courneya, L. C. Mâsse, S. Duval, and K. H. Schmitz, "An update of controlled physical activity trials in cancer survivors: a systematic review and meta-analysis," Journal of Cancer Survivorship, vol. 4, no. 2, pp. 87-100, 2010.

[15] W. Demark-Wahnefried and L. W. Jones, "Promoting a Healthy Lifestyle Among Cancer Survivors," Hematology/Oncology Clinics of North America, vol. 22, no. 2, pp. 319-342, 2008.

[16] R. A. Ferrer, T. B. Huedo-Medina, B. T. Johnson, S. Ryan, and L. S. Pescatello, "Exercise interventions for cancer survivors: a meta-analysis of quality of life outcomes," Annals of Behavioral Medicine, vol. 41, no. 1, pp. 32-47, 2011.

[17] D. Y. T. Fong, J. W. C. Ho, and B. P. H. Hui, "Physical activity for cancer survivors: meta-analysis of randomised controlled trials," British Medical Journal, vol. 344, article e70, 2012.

[18] J. R. Gardner, P. M. Livingston, and S. F. Fraser, "Effects of exercise on treatment-related adverse effects for patients with prostate cancer receiving androgen-deprivation therapy: A systematic review," Journal of Clinical Oncology, vol. 32, no. 4, pp. 335-346, 2014.

[19] S. I. Mishra, R. W. Scherer, C. Snyder, P. Geigle, and C. Gotay, "Are exercise programs effective for improving health-related quality of life among cancer survivors? A systematic review and meta-analysis," Oncology Nursing Forum, vol. 41, no. 6, pp. E326-E342, 2014.

[20] C. L. Rock, C. Doyle, W. Demark-Wahnefried et al., "Nutrition and physical activity guidelines for cancer survivors," $C A$ : $A$ Cancer Journal for Clinicians, vol. 62, no. 4, pp. 242-274, 2012.

[21] K. H. Schmitz, K. S. Courneya, and C. Matthews, "Erratum: American college of sports medicine roundtable on exercise guidelines for cancer survivors (Medicine and Science in Sports and Exercise (2010) 42: 7 (1409-1426))," Medicine \& Science in Sports \& Exercise, vol. 43, no. 1, p. 195, 2011.

[22] J. F. Meneses-Echávez, E. González-Jiménez, and R. RamírezVélez, "Effects of supervised exercise on cancer-related fatigue in breast cancer survivors: a systematic review and metaanalysis," BMC Cancer, vol. 15, p. 77, 2015.

[23] A. M. Dennett, C. L. Peiris, N. Shields, L. A. Prendergast, and N. F. Taylor, "Moderate-intensity exercise reduces fatigue and improves mobility in cancer survivors: A systematic review and meta-regression," Journal of Physiotherapy, vol. 62, no. 2, pp. 6882, 2016.
[24] K. M. Mustian, C. M. Alfano, C. Heckler et al., "Comparison of pharmaceutical, psychological, and exercise treatments for cancer-related fatigue: A meta-analysis," JAMA Oncology, vol. 3, no. 7, pp. 961-968, 2017.

[25] L. W. Jones and C. M. Alfano, "Exercise-oncology research: Past, present, and future," Acta Oncologica, vol. 52, no. 2, pp. 195-215, 2013.

[26] H. Arem, R. M. Pfeiffer, E. A. Engels et al., "Pre- and postdiagnosis physical activity, television viewing, and mortality among patients with colorectal cancer in the national institutes of health-AARP diet and health study," Journal of Clinical Oncology, vol. 33, no. 2, pp. 180-188, 2015.

[27] H. Arem, S. C. Moore, A. Patel et al., "Leisure time physical activity and mortality: a detailed pooled analysis of the doseresponse relationship," JAMA Internal Medicine, vol. 175, no. 6, pp. 959-967, 2015.

[28] A. S. Betof, M. W. Dewhirst, and L. W. Jones, "Effects and potential mechanisms of exercise training on cancer progression: A translational perspective," Brain, Behavior, and Immunity, vol. 30, pp. S75-S87, 2013.

[29] K. S. Courneya, C. M. Sellar, C. Stevinson et al., "Randomized controlled trial of the effects of aerobic exercise on physical functioning and quality of life in lymphoma patients," Journal of Clinical Oncology, vol. 27, no. 27, pp. 4605-4612, 2009.

[30] E. M. Ibrahim and A. Al-Homaidh, "Physical activity and survival after breast cancer diagnosis: meta-analysis of published studies," Medical Oncology, vol. 28, no. 3, pp. 753-765, 2011.

[31] S. A. Kenfield, M. J. Stampfer, E. Giovannucci, and J. M. Chan, "Physical activity and survival after prostate cancer diagnosis in the health professionals follow-up study," Journal of Clinical Oncology, vol. 29, no. 6, pp. 726-732, 2011.

[32] L. N. Kohler, D. O. Garcia, R. B. Harris, E. Oren, D. J. Roe, and E. T. Jacobs, "Adherence to diet and physical activity cancer prevention guidelines and cancer outcomes: A systematic review," Cancer Epidemiology, Biomarkers \& Prevention, vol. 25, no. 7, pp. 1018-1028, 2016.

[33] I. M. Lahart, G. S. Metsios, A. M. Nevill, and A. R. Carmichael, "Physical activity, risk of death and recurrence in breast cancer survivors: a systematic review and meta-analysis of epidemiological studies," Acta Oncologica, vol. 54, no. 5, pp. 635-654, 2015.

[34] J. Ligibel, "Lifestyle factors in cancer survivorship," Journal of Clinical Oncology, vol. 30, no. 30, pp. 3697-3704, 2012.

[35] J. A. Meyerhardt, D. Heseltine, D. Niedzwiecki et al., "Impact of physical activity on cancer recurrence and survival in patients with stage III colon cancer: Findings from CALGB 89803," Journal of Clinical Oncology, vol. 24, no. 22, pp. 3535-3541, 2006.

[36] J. A. Meyerhardt, J. Ma, and K. S. Courneya, "Energetics in colorectal and prostate cancer," Journal of Clinical Oncology, vol. 28, no. 26, pp. 4066-4073, 2010.

[37] S. C. Moore, I.-M. Lee, E. Weiderpass et al., "Association of leisure-time physical activity with risk of 26 types of cancer in 1.44 million adults," JAMA Internal Medicine, vol. 176, no. 6, pp. 816-825, 2016.

[38] D. Schmid and M. F. Leitzmann, "Association between physical activity and mortality among breast cancer and colorectal cancer survivors: a systematic review and meta-analysis," Annals of Oncology, vol. 25, no. 7, Article ID mdu012, pp. 1293-1311, 2014.

[39] P. T. Williams, "Significantly greater reduction in breast cancer mortality from post-diagnosis running than walking," International Journal of Cancer, vol. 135, no. 5, pp. 1195-1202, 2014. 
[40] P. T. Campbell, A. V. Patel, C. C. Newton, E. J. Jacobs, and S. M. Gapstur, "Associations of recreational physical activity and leisure time spent sitting with colorectal cancer survival," Journal of Clinical Oncology, vol. 31, no. 7, pp. 876-885, 2013.

[41] A. Ariza-García, N. Galiano-Castillo, I. Cantarero-Villanueva, C. Fernández-Lao, L. Díaz-Rodríguez, and M. Arroyo-Morales, "Influence of physical inactivity in psychophysiolocigal state of breast cancer survivors," European Journal of Cancer Care, vol. 22, no. 6, pp. 738-745, 2013.

[42] A. Biswas, P. I. Oh, G. E. Faulkner et al., "Sedentary time and its association with risk for disease incidence, mortality, and hospitalization in adults: a systematic review and metaanalysis," Annals of Internal Medicine, vol. 162, no. 2, pp. 123-132, 2015.

[43] R. A. Cannioto, M. LaMonte, and K. B. Moysich, "Abstract B18: Prediagnostic physical inactivity and epithelial ovarian cancer risk and mortality: Evidence from the Ovarian Cancer Association Consortium.," Clinical Cancer Research, vol. 22, no. 2 Supplement, pp. B18-B18, 2016.

[44] S. M. George, C. M. Alfano, J. Groves et al., "Objectively measured sedentary time is related to quality of life among cancer survivors," PLoS ONE, vol. 9, no. 2, Article ID e87937, 2014.

[45] A. V. Patel, J. S. Hildebrand, P. T. Campbell et al., "Leisure-time spent sitting and site-specific cancer incidence in a large U.S. Cohort," Cancer Epidemiology, Biomarkers \& Prevention, vol. 24, no. 9, pp. 1350-1359, 2015.

[46] D. Schmid and M. F. Leitzmann, "Television viewing and time spent sedentary in relation to cancer risk: A meta-analysis," Journal of the National Cancer Institute, vol. 106, no. 7, Article ID dju098, 2014.

[47] D. Shen, W. Mao, T. Liu et al., "Sedentary behavior and incident cancer: A meta-analysis of prospective studies," PLoS ONE, vol. 9, no. 8, Article ID e105709, 2014.

[48] C. K. Blair, M. C. Morey, R. A. Desmond et al., "Light-intensity activity attenuates functional decline in older cancer survivors," Medicine \& Science in Sports \& Exercise, vol. 46, no. 7, pp. 13751383, 2014.

[49] W. Lu and D. S. Rosenthal, "Acupuncture for cancer pain and related symptoms.," Current Pain and Headache Reports, vol. 17, no. 3, p. 321, 2013.

[50] M. Eghbali, M. S. Yekaninejad, S. varaei, S. F. Jalalinia, M. A. Samimi, and K. Sa'atchi, "The effect of auricular acupressure on nausea and vomiting caused by chemotherapy among breast cancer patients," Complementary Therapies in Clinical Practice, vol. 24, pp. 189-194, 2016.

[51] X. Han, L. Wang, H. Zheng et al., "Acupuncture combined with methylcobalamin for the treatment of chemotherapy-induced peripheral neuropathy in patients with multiple myeloma," BMC Cancer, vol. 17, no. 1, p. 40, 2017.

[52] Adult Cancer Pain (Version 2.2016), "National Comprehensive Cancer Network," 2017, https:/www.nccn.org/professionals/physician gls/pdf/pain.pdf.

[53] J. J. Mao, C. Stricker, J. Farrar et al., "A randomized trial of electro-acupuncture for arthralgia related to aromatase inhibitor use," Eur J Cancer, vol. 50, no. 2, pp. 267-276, 2014.

[54] T. Bao, L. Cai, C. Snyder et al., "Patient-reported outcomes in women with breast cancer enrolled in a dual-center, doubleblind, randomized controlled trial assessing the effect of acupuncture in reducing aromatase inhibitor-induced musculoskeletal symptoms," Cancer, vol. 120, no. 3, pp. 381-389, 2014.
[55] X. Meng, Y. Zhang, A. Li et al., "The effects of opioid receptor antagonists on electroacupuncture-produced antiallodynia/hyperalgesia in rats with paclitaxel-evoked peripheral neuropathy," Brain Research, vol. 1414, pp. 58-65, 2011.

[56] National Comprehensive Cancer Network, "Antiemesis (Version 2.2016)," 2017, https://www.nccn.org/professionals/physician_gls/ pdf/antiemesis.pdf.

[57] X. Wu, V. C. Chung, E. P. Hui et al., "Effectiveness of acupuncture and related therapies for palliative care of cancer: overview of systematic reviews," Scientific Reports, vol. 5, no. 1, 2015.

[58] M. K. Garcia, L. Cohen, M. Spano et al., "Inpatient Acupuncture at a Major Cancer Center. Integr Cancer Ther," OctoberDecember, p. 1, 2016.

[59] D. Tas, D. Uncu, M. A. Sendur, N. Koca, and N. Zengin, "Acupuncture as a complementary treatment for cancer patients receiving chemotherapy," Asian Pacific Journal of Cancer Prevention, vol. 15, no. 7, pp. 3139-3144, 2014.

[60] F. A. Morschhauser, G. Cartron, and C. Thieblemont, "Systematic review of acupuncture in cancer care: a synthesis of the evidence," Journal of Clinical Oncology, vol. 37, no. 7, pp. 952960, 2013.

[61] D. O'Regan and J. Filshie, "Acupuncture and Cancer," Acupuncture and Cancer. Auton Neruosci, vol. 152, no. 1-2, pp. 96-100, 2010.

[62] A. J. Cohen, A. Menter, and L. Hale, "Acupuncture: Role in comprehensive cancer care - A primer for the oncologist and review of the literature," Integrative Cancer Therapies, vol. 4, no. 2, pp. 131-143, 2005.

[63] Y. Ma, M. Dong, K. Zhou, C. Mita, J. Liu, and P. M. Wayne, "Publication Trends in Acupuncture Research: A 20-Year Bibliometric Analysis Based on PubMed," PLos One, vol. 11, no. 2, 2016.

[64] B. Oh, T. Eade, A. Kneebone et al., "Factors affecting whether or not cancer patients consider using acupuncture," Accupunct Med, Article ID 011115, p. 2016, 2016.

[65] M. M. Stanczyk, "Music therapy in supportive cancer care," Reports of Practical Oncology and Radiotherapy, vol. 16, no. 5, pp. 170-172, 2011.

[66] M. M. Richardson, A. E. Babiak-Vazquez, and M. A. Frenkel, "Music therapy in a comprehensive cancer center," J Soc Integr Oncol, vol. 6, no. 2, pp. 76-81, 2008.

[67] M. S. Cepeda, D. B. Carr, J. Lau, and H. Alvarez, "Music for pain relief," Cochrane Database of Systematic Reviews (Online), no. 2, p. CD004843, 2006.

[68] H. Greenlee, L. G. Balneaves, L. E. Carlson et al., "Clinical Practice Guidelines on the Use of Integrative Therapies as Supportive Care in Patients Treated for Breast Cancer," JNCI Monographs, vol. 2014, no. 50, pp. 346-358, 2014.

[69] S. Kordovan, P. Preissler, A. Kamphausen, C. Bokemeyer, and K. Oechsle, "Prospective Study on Music Therapy in Terminally Ill Cancer Patients during Specialized Inpatient Palliative Care," Journal of Palliative Medicine, vol. 19, no. 4, pp. 394-399, 2016.

[70] K. Boehm, H. Cramer, T. Staroszynski, and T. Ostermann, "Arts therapies for anxiety, depression, and quality of life in breast cancer patients: A systematic review and meta-analysis," Evidence-Based Complementary and Alternative Medicine, vol. 2014, Article ID 103297, 2014.

[71] O. Olaku and J. D. White, "Herbal therapy use by cancer patients: a literature review on case reports," European Journal of Cancer, vol. 47, no. 4, pp. 508-514, 2011. 
[72] E. Ben-Arye, S. Attias, T. Tadmor, and E. Schiff, "Herbs in hemato-oncological care: An evidence-based review of data on efficacy, safety, and drug interactions," Leukemia \& Lymphoma, vol. 51, no. 8, pp. 1414-1423, 2010.

[73] T. D. Shanafelt, Y. K. Lee, T. G. Call et al., "Clinical effects of oral green tea extracts in four patients with low grade B-cell malignancies," Leukemia Research, vol. 30, no. 6, pp. 707-712, 2006.

[74] H. D. Hoon, J. H. Jeong, and H. J. Kim, "Anti-proliferative and apoptosis induction activity of green tea polyphenols on human promyelocytic leukemia HL-60 cells," Anticancer Reseach, vol. 29, no. 4, pp. 1417-1422, 2009.

[75] Y. K. Lee, N. D. Bone, A. K. Strege, T. D. Shanafelt, D. F. Jelinek, and N. E. Kay, "VEGF receptor phosphorylation status and apoptosis is modulated by a green tea component, epigallocatechin-3-gallate (EGCG), in B-cell chronic lymphocytic leukemia," Blood, vol. 104, no. 3, pp. 788-794, 2004.

[76] L.-Y. Khil, W. Kim, S. Lyu, W. B. Park, J.-W. Yoon, and H.-S. Jun, "Mechanisms involved in Korean mistletoe lectin-induced apoptosis of cancer cells," World Journal of Gastroenterology, vol. 13, no. 20, pp. 2811-2818, 2007.

[77] K. Urech, A. Buessing, G. Thalmann, H. Schaefermeyer, and P. Heusser, "Antiproliferative effects of mistletoe (Viscum album L.) extract in urinary bladder carcinoma cell lines," Anticancer Reseach, vol. 26, no. 4 B, pp. 3049-3055, 2006.

[78] U. Valentiner, U. Pfüller, C. Baum, and U. Schumacher, "The cytotoxic effect of mistletoe lectins I, II and III on sensitive and multidrug resistant human colon cancer cell lines in vitro," Toxicology, vol. 171, no. 2-3, pp. 187-199, 2002.

[79] S. R. Elluru, J.-P. D. Van Huyen, S. Delignat et al., "Antiangiogenic properties of Viscum album extracts are associated with endothelial cytotoxicity," Anticancer Reseach, vol. 29, no. 8, pp. 2945-2950, 2009.

[80] U. Elsässer-Beile, C. Leiber, U. Wetterauer et al., "Adjuvant intravesical treatment with a standardized mistletoe extract to prevent recurrence of superficial urinary bladder cancer," Anticancer Reseach, vol. 25, no. 6 C, pp. 4733-4736, 2005.

[81] Mistletoe Extracts, Health Professional Version, PDQ Cancer Information Summaries, Bethesda, 2002.

[82] D. M. Hansra, O. Silva, A. Mehta, and E. Ahn, "Patient with Metastatic Breast Cancer Achieves Stable Disease for 5 Years on Graviola and Xeloda after Progressing on Multiple Lines of Therapy," Advances in Breast Cancer Research, vol. 03, no. 03, pp. 84-87, 2014.

[83] M. A. Horneber, G. Bueschel, R. Huber, K. Linde, and M. Rostock, "Mistletoe therapy in oncology.", Cochrane Database of Systematic Reviews (Online), no. 2, p. CD003297, 2008.

[84] G. S. Kienle and H. Kiene, "Complementary cancer therapy: a systematic review of prospective clinical trials on anthroposophic mistletoe extracts," European Journal of Medical Research, vol. 12, no. 3, pp. 103-119, 2007.

[85] P. R. Bock, W. E. Friedel, J. Hanisch, M. Karasmann, and B. Schneider, "Efficacy and safety of long-term complementary treatment with standardized european mistletoe extract (Viscum album L.) in addition to the conventional adjuvant oncologic therapy in patients with primary non-metastasized mammary carcinoma/results of a multicenter, comparative, epidemiological cohort study in Germany and Switzerland," Arzneimittel-Forschung/Drug Research, vol. 54, no. 8, pp. 456466, 2004.

[86] G. S. Kienle and H. Kiene, "Influence of Viscum album L (European mistletoe) extracts on quality of life in cancer patients: a systematic review of controlled clinical studies," Integrative Cancer Therapies, vol. 9, no. 2, pp. 142-157, 2010.

[87] G. S. Kienle, A. Glockmann, M. Schink, and H. Kiene, "Viscum album L. extracts in breast and gynaecological cancers: a systematic review of clinical and preclinical research," Journal of Experimental \& Clinical Cancer Research, vol. 28, no. 1, article 79, 2009.

[88] B. K. Piao, Y. X. Wang, G. R. Xie et al., "Impact of complementary mistletoe extract treatment on quality of life in breast, ovarian and non-small cell lung cancer patients. A prospective randomized controlled clinical trial," Anticancer Reseach, vol. 24, no. 1, pp. 303-309, 2004.

[89] S. M. Zick, M. T. Ruffin, J. Lee et al., "Phase II trial of encapsulated ginger as a treatment for chemotherapy-induced nausea and vomiting," Supportive Care in Cancer, vol. 17, no. 5, pp. 563-572, 2009.

[90] M. E. Levine, M. G. Gillis, S. Y. Koch, A. C. Voss, R. M. Stern, and K. L. Koch, "Protein and ginger for the treatment of chemotherapy-induced delayed nausea," The Journal of Alternative and Complementary Medicine, vol. 14, no. 5, pp. 545-551, 2008.

[91] W. Marx, K. Ried, A. L. McCarthy et al., "Ginger-Mechanism of action in chemotherapy-induced nausea and vomiting: A review," Critical Reviews in Food Science and Nutrition, vol. 57, no. 1, pp. 141-146, 2017.

[92] K. Linde, M. M. Berner, and L. Kriston, “St John's wort for major depression.," Cochrane Database of Systematic Reviews (Online), no. 4, p. CD000448, 2008.

[93] M. H. Pittler and E. Ernst, "Kava extract for treating anxiety.", Cochrane Database of Systematic Reviews (Online), no. 1, p. CD003383, 2003.

[94] S. Witte, D. Loew, and W. Gaus, "Meta-analysis of the efficacy of the acetonic kava-kava extract WS ${ }^{\circledR} 1490$ in patients with nonpsychotic anxiety disorders," Phytotherapy Research, vol. 19, no. 3, pp. 183-188, 2005.

[95] A. Sparreboom, M. C. Cox, M. R. Acharya, and W. D. Figg, "Herbal remedies in the United States: potential adverse interactions with anticancer agents," Journal of Clinical Oncology, vol. 22, no. 12, pp. 2489-2503, 2004.

[96] D. L. Clouatre, "Kava kava: Examining new reports of toxicity," Toxicology Letters, vol. 150, no. 1, pp. 85-96, 2004.

[97] W. K. Oh, P. W. Kantoff, V. Weinberg et al., "Prospective, multicenter, randomized phase II trial of the herbal supplement, PC-SPES, and diethylstilbestrol in patients with androgenindependent prostate cancer," Journal of Clinical Oncology, vol. 22, no. 18, pp. 3705-3712, 2004.

[98] T. Ikezoe, S. Chen, T. Saito et al., "PC-SPES decreases proliferation and induces differentiation and apoptosis of human acute myeloid leukemia cells.," International Journal of Oncology, vol. 23, no. 4, pp. 1203-1211, 2003.

[99] M. Shabbir, J. Love, and B. Montgometry, "Phase I trial of PC-Spes2 in advanced hormone refractory prostate cancer," Oncology Reports, vol. 19, no. 3, pp. 831-835, 2008.

[100] M. C. Weinrobe and B. Montgomery, "Acquired bleeding diathesis in a patient taking PC-SPES [4]," The New England Journal of Medicine, vol. 345, no. 16, pp. 1213-1214, 2001.

[101] M. Inoue-Choi, H. Greenlee, S. J. Oppeneer, and K. Robien, "The association between postdiagnosis dietary supplement use and total mortality differs by diet quality among older female cancer survivors," Cancer Epidemiology, Biomarkers \& Prevention, vol. 23, no. 5, pp. 865-875, 2014. 
[102] C. M. Velicer and C. M. Ulrich, "Vitamin and mineral supplement use among US adults after cancer diagnosis: a systematic review," Journal of Clinical Oncology, vol. 26, no. 4, pp. 665-673, 2008.

[103] G. M. John, D. L. Hershman, L. Falci, Z. Shi, W.-Y. Tsai, and H. Greenlee, "Complementary and alternative medicine use among US cancer survivors," Journal of Cancer Survivorship, vol. 10, no. 5, pp. 850-864, 2016.

[104] P. A. Cohen, G. Maller, R. DeSouza, and J. Neal-Kababick, "Presence of banned drugs in dietary supplements following FDA recalls," Journal of the American Medical Association, vol. 312, no. 16, pp. 1691-1693, 2014.

[105] C. Carroll, K. Cooper, D. Papaioannou, D. Hind, H. Pilgrim, and P. Tappenden, "Supplemental calcium in the chemoprevention of colorectal cancer: A systematic review and meta-analysis," Clinical Therapeutics, vol. 32, no. 5, pp. 789-803, 2010.

[106] H. R. Harris, N. Orsini, and A. Wolk, "Vitamin C and survival among women with breast cancer: A Meta-analysis," European Journal of Cancer, vol. 50, no. 7, pp. 1223-1231, 2014.

[107] S. M. Sagar, T. Dryden, and R. K. Wong, "Massage therapy for cancer patients: A reciprocal relationship between body and mind," Current Oncology, vol. 14, no. 2, pp. 45-56, 2007.

[108] B. R. Cassileth and A. J. Vickers, "Massage therapy for symptom control: outcome study at a major cancer center," Journal of Pain and Symptom Management, vol. 28, no. 3, pp. 244-249, 2004.

[109] A. Billhult, I. Bergbom, and E. Stener-Victorin, "Massage relieves nausea in women with breast cancer who are undergoing chemotherapy," The Journal of Alternative and Complementary Medicine, vol. 13, no. 1, pp. 53-57, 2007.

[110] M. Listing, A. Reißhauer, M. Krohn et al., "Massage therapy reduces physical discomfort and improves mood disturbances in women with breast cancer," Psycho-Oncology, vol. 18, no. 12, pp. 1290-1299, 2009.

[111] M. Listing, M. Krohn, C. Liezmann et al., "The efficacy of classical massage on stress perception and cortisol following primary treatment of breast cancer," Archives of Women's Mental Health, vol. 13, no. 2, pp. 165-173, 2010.

[112] M. Hernandez-Reif, G. Ironson, T. Field et al., "Breast cancer patients have improved immune and neuroendocrine functions following massage therapy," Journal of Psychosomatic Research, vol. 57, no. 1, pp. 45-52, 2004.

[113] M. Krohn, M. Listing, G. Tjahjono et al., "Depression, mood, stress, and Th1/Th2 immune balance in primary breast cancer patients undergoing classical massage therapy," Supportive Care in Cancer, vol. 19, no. 9, pp. 1303-1311, 2011.

[114] Y. Q. Pan, K. H. Yang, Y. L. Wang, L. P. Zhang, and H. Q. Liang, "Massage interventions and treatment-related side effects of breast cancer: a systematic review and meta-analysis," International Journal of Clinical Oncology, vol. 19, no. 5, pp. 829841, 2014.

[115] E.-S. Shin, K.-H. Seo, S.-H. Lee et al., "Massage with or without aromatherapy for symptom relief in people with cancer," Cochrane Database of Systematic Reviews, vol. 2016, no. 6, Article ID CD009873, 2016.

[116] S. Wilkinson, K. Barnes, and L. Storey, "Massage for symptom relief in patients with cancer: Systematic review," Journal of Advanced Nursing, vol. 63, no. 5, pp. 430-439, 2008.

[117] J. J. Mao, K. E. Wagner, C. M. Seluzicki et al., "Integrating oncology massage into chemoinfusion suites: A program evaluation," Journal of Oncology Practice, vol. 13, no. 3, pp. e207-e216, 2017.
[118] J. L. C. Lee, L. P. Leong, and S. L. Lim, "Nutrition intervention approaches to reduce malnutrition in oncology patients: a systematic review," Supportive Care in Cancer, vol. 24, no. 1, pp. 469-480, 2016.

[119] K. Sánchez-Lara, J. G. Turcott, E. Juárez et al., "Association of nutrition parameters including bioelectrical impedance and systemic inflammatory response with quality of life and prognosis in patients with advanced non-small-cell lung cancer: a prospective study," Nutrition and Cancer, vol. 64, no. 4, pp. 526534, 2012.

[120] M. D. D. S. Costa, C. Y. S. Vieira de Melo, A. C. R. D. Amorim, D. D. O. Cipriano Torres, and A. C. O. dos Santos, "Association Between Nutritional Status, Inflammatory Condition, and Prognostic Indexes with Postoperative Complications and Clinical Outcome of Patients with Gastrointestinal Neoplasia," Nutrition and Cancer, vol. 68, no. 7, pp. 1108-1114, 2016.

[121] S. L. Hofbauer, A. J. Pantuck, M. de Martino et al., "The preoperative prognostic nutritional index is an independent predictor of survival in patients with renal cell carcinoma," Urologic Oncology: Seminars and Original Investigations, vol. 33, no. 2, pp. 68.e1-68.e7, 2015.

[122] N. Jiang, J.-Y. Deng, X.-W. Ding et al., "Prognostic nutritional index predicts postoperative complications and long-term outcomes of gastric cancer," World Journal of Gastroenterology, vol. 20, no. 30, pp. 10537-10544, 2014.

[123] R. C. R. Albuquerque, V. T. Baltar, and D. M. L. Marchioni, "Breast cancer and dietary patterns: A systematic review," Nutrition Reviews, vol. 72, no. 1, pp. 1-17, 2014.

[124] P. Bertuccio, V. Rosato, A. Andreano et al., "Dietary patterns and gastric cancer risk: A systematic review and meta-analysis," Annals of Oncology, vol. 24, no. 6, pp. 1450-1458, 2013.

[125] O. Oyebode, V. Gordon-Dseagu, A. Walker, and J. S. Mindell, "Fruit and vegetable consumption and all-cause, cancer and CVD mortality: analysis of health survey for England data," Journal of Epidemiology and Community Health, vol. 68, no. 9, pp. 856-862, 2014.

[126] J. A. Meyerhardt, D. Niedzwiecki, D. Hollis et al., "Association of dietary patterns with cancer recurrence and survival in patients with stage III colon cancer," Journal of the American Medical Association, vol. 298, no. 7, pp. 754-764, 2007.

[127] J. A. Meyerhardt, K. Sato, D. Niedzwiecki et al., "Dietary glycemic load and cancer recurrence and survival in patients with stage III colon cancer: Findings from CALGB 89803," Journal of the National Cancer Institute, vol. 104, no. 22, pp. 1702-1711, 2012.

[128] M. L. McCullough, S. M. Gapstur, R. Shah, E. J. Jacobs, and P. T. Campbell, "Association between red and processed meat intake and mortality among colorectal cancer survivors," Journal of Clinical Oncology, vol. 31, no. 22, pp. 2773-2782, 2013.

[129] G.-C. Chen, X. Tong, J.-Y. Xu et al., "Whole-grain intake and total, cardiovascular, and cancer mortality: A systematic review and meta-analysis of prospective studies," American Journal of Clinical Nutrition, vol. 104, no. 1, pp. 164-172, 2016.

[130] H.-J. Jia, P.-J. Zhang, Y.-L. Liu, C.-G. Jiang, X. Zhu, and Y.-P. Tian, "Relationship of serum polyunsaturated fatty acids with cytokines in colorectal cancer," World Journal of Gastroenterology, vol. 22, no. 8, pp. 2524-2532, 2016.

[131] Y.-J. Ma, J. Yu, J. Xiao, and B.-W. Cao, “The consumption of omega-3 polyunsaturated fatty acids improves clinical outcomes and prognosis in pancreatic cancer patients: A systematic evaluation," Nutrition and Cancer, vol. 67, no. 1, pp. 112-118, 2015. 
[132] E. Toledo, J. Salas-Salvado, C. Donat-Vargas et al., "Mediterranean diet and invasive breast cancer risk among women at high cardiovascular risk in the predimed trial a randomized clinical trial," JAMA Internal Medicine, vol. 175, no. 11, pp. 17521760, 2015.

[133] D. S. M. Chan, A. R. Vieira, D. Aune et al., "Body mass index and survival in women with breast cancer-systematic literature review and meta-analysis of 82 follow-up studies," Annals of Oncology, vol. 25, no. 10, pp. 1901-1914, 2014.

[134] J. J. Dignam, B. N. Polite, G. Yothers et al., "Body mass index and outcomes in patients who receive adjuvant chemotherapy for colon cancer," Journal of the National Cancer Institute, vol. 98, no. 22, pp. 1647-1654, 2006.

[135] B. J. Caan, M. L. Kwan, X. O. Shu et al., "Weight change and survival after breast cancer in the after breast cancer pooling project," Cancer Epidemiology, Biomarkers \& Prevention, vol. 21, no. 8, pp. 1260-1271, 2012.

[136] J. M. Salsman, J. E. Pustejovsky, H. S. L. Jim et al., "A metaanalytic approach to examining the correlation between religion/spirituality and mental health in cancer," Cancer, vol. 121, no. 21, pp. 3769-3778, 2015.

[137] K. M. Piderman, M. E. Johnson, M. H. Frost et al., "Spiritual quality of life in advanced cancer patients receiving radiation therapy," Psycho-Oncology, vol. 23, no. 2, pp. 216-221, 2014.

[138] S. Hematti, M. Baradaran-Ghahfarokhi, R. Khajooei-Fard, and Z. Mohammadi-Bertiani, "Spiritual Well-Being for Increasing Life Expectancy in Palliative Radiotherapy Patients: A Questionnaire-Based Study, Journal of Religion and Health, vol. 54, no. 5, pp. 1563-1572, 2015.

[139] A.-L. Williams, J. Dixon, R. Feinn, and R. McCorkle, "Cancer family caregiver depression: Are religion-related variables important?" Psycho-Oncology, vol. 24, no. 7, pp. 825-831, 2015.

[140] S. Li, M. J. Stampfer, D. R. Williams, and T. J. Vanderweele, "Association of religious service attendance with mortality amongWomen," JAMA Internal Medicine, vol. 176, no. 6, pp. 777-785, 2016.

[141] P.-J. Oh and S. H. Kim, "The effects of spiritual interventions in patients with cancer: A meta-analysis," Oncology Nursing Forum, vol. 41, no. 5, pp. E290-E301, 2014.

[142] C. L. Petersen, "Spiritual care of the child with cancer at the end of life: A concept analysis," Journal of Advanced Nursing, vol. 70, no. 6, pp. 1243-1253, 2014.

[143] T. A. Balboni, L. C. Vanderwerker, S. D. Block et al., "Religiousness and spiritual support among advanced cancer patients and associations with end-of-life treatment preferences and quality of life," Journal of Clinical Oncology, vol. 25, no. 5, pp. 555-560, 2007.

[144] A. B. Astrow, A. Wexler, K. Texeira, M. Kai He, and D. P. Sulmasy, "Is failure to meet spiritual needs associated with cancer patients' perceptions of quality of care and their satisfaction with care?" Journal of Clinical Oncology, vol. 25, no. 36, pp. 5753-5757, 2007.

[145] J. A. Schreiber and D. Y. Brockopp, "Twenty-five years laterwhat do we know about religion/spirituality and psychological well-being among breast cancer survivors? A systematic review," Journal of Cancer Survivorship, vol. 6, no. 1, pp. 82-94, 2012.

[146] M. King, H. Llewellyn, B. Leurent et al., "Spiritual beliefs near the end of life: A prospective cohort study of people with cancer receiving palliative care," Psycho-Oncology, vol. 22, no. 11, pp. 2505-2512, 2013.

[147] B. McLaughlin, W. Yoo, J. D’Angelo et al., "It is out of my hands: How deferring control to God can decrease quality of life for breast cancer patients," Psycho-Oncology, vol. 22, no. 12, pp. 2747-2754, 2013.

[148] H. S. L. Jim, J. E. Pustejovsky, C. L. Park et al., "Religion, spirituality, and physical health in cancer patients: A metaanalysis," Cancer, vol. 121, no. 21, pp. 3760-3768, 2015.

[149] A. C. Sherman, T. V. Merluzzi, J. E. Pustejovsky et al., "A metaanalytic review of religious or spiritual involvement and social health among cancer patients," Cancer, vol. 121, no. 21, pp. 37793788, 2015.

[150] J. M. Salsman, G. Fitchett, T. V. Merluzzi, A. C. Sherman, and C. L. Park, "Religion, spirituality, and health outcomes in cancer: A case for a meta-analytic investigation," Cancer, vol. 121, no. 21, pp. 3754-3759, 2015.

[151] D. M. Hansra et al., "Evaluation of Hematology/Oncology Patient and Physician Expectations for Integrative Oncology at a Tertiary Care Center," Journal of Clinical Oncology, vol. 34, no. 5, pp. 488-494, 2016. 


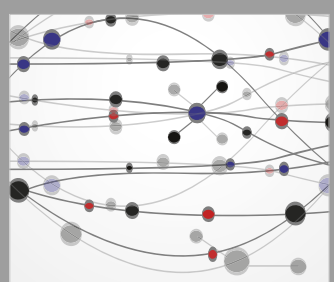

The Scientific World Journal
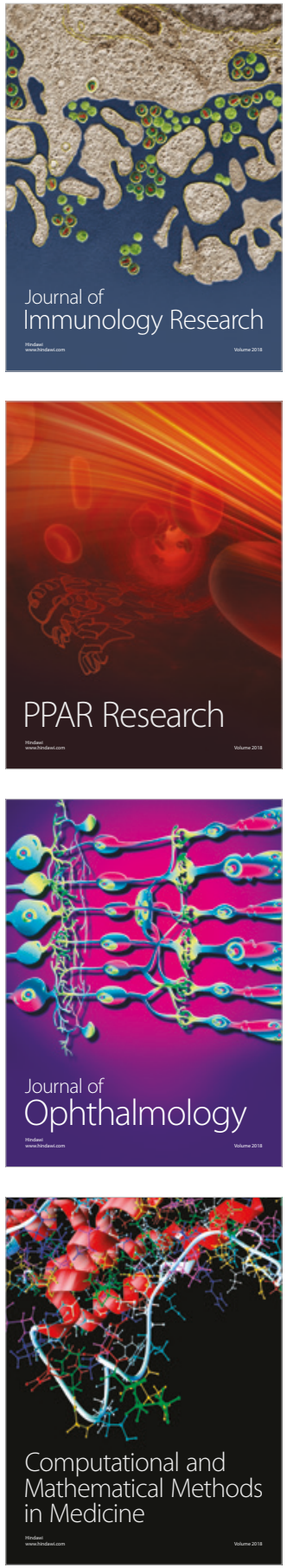

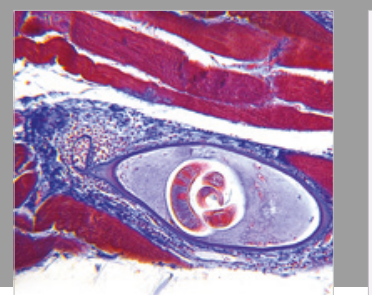

Gastroenterology Research and Practice

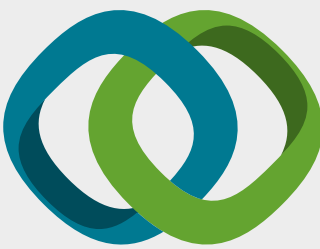

\section{Hindawi}

Submit your manuscripts at

www.hindawi.com
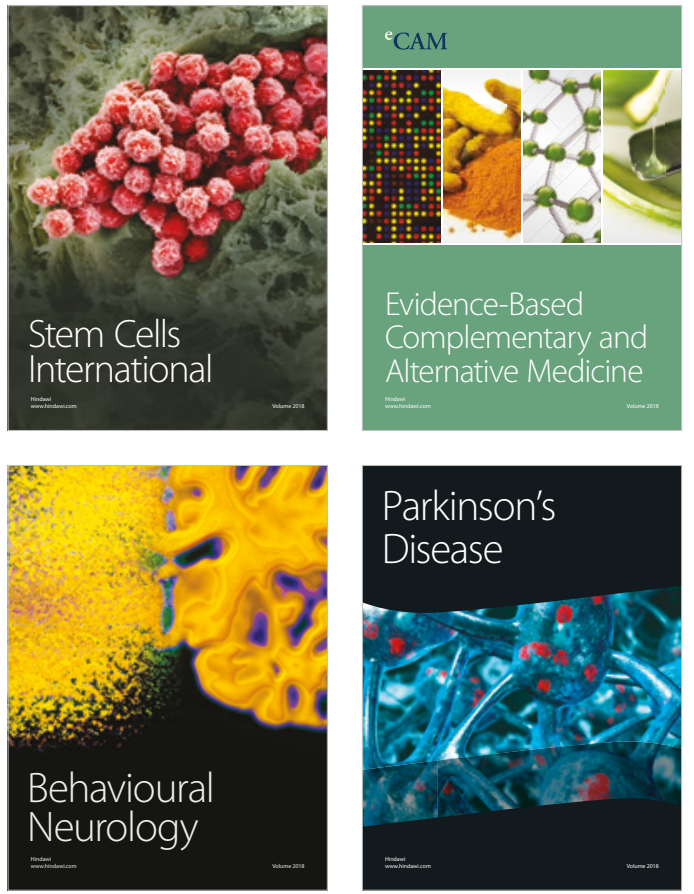

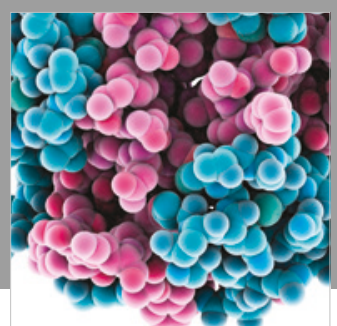

ournal of

Diabetes Research

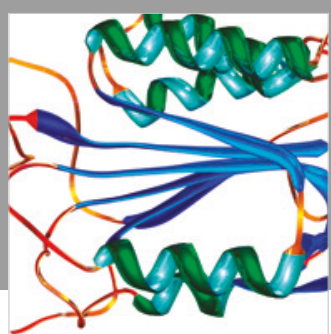

Disease Markers
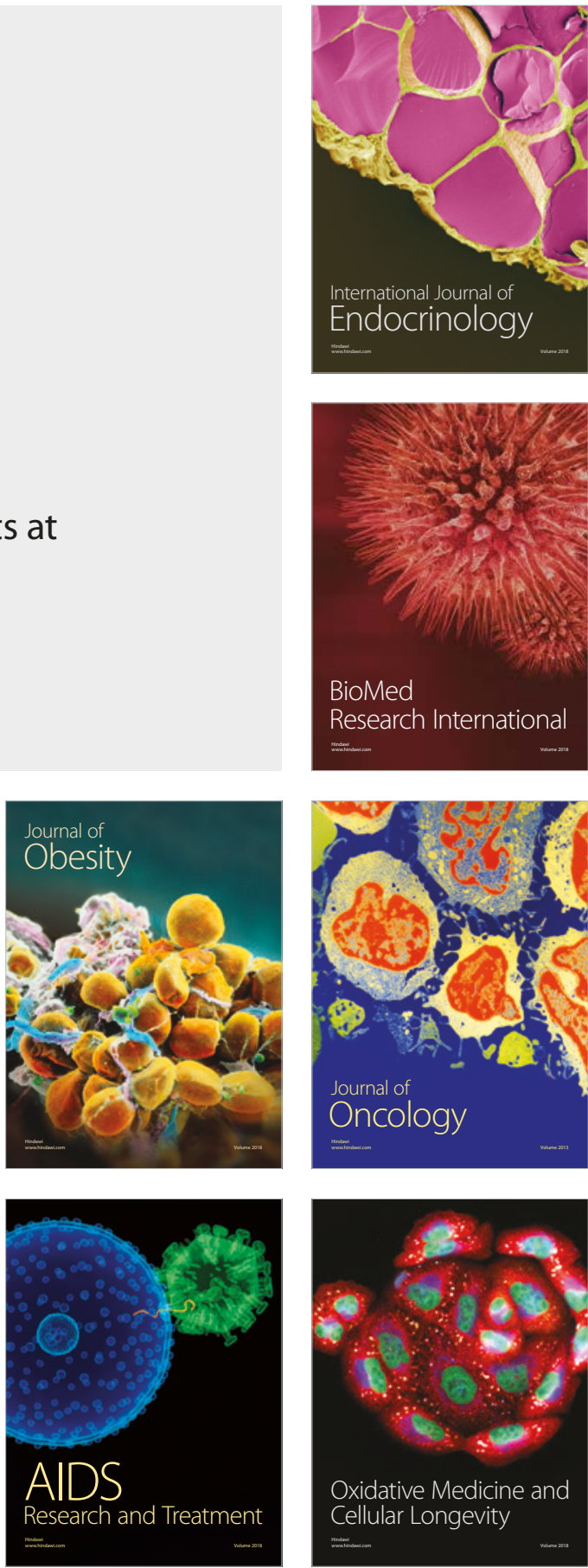